\title{
Leukotriene $B_{4}$ synthesis and metabolism by neutrophils and granule-free cytoplasts
}

\author{
Kathleen A. HAINES, ${ }^{*} \ddagger$ Kenneth N. GIEDD $\dagger$ and Gerald WEISSMANN $\dagger$ \\ *Department of Pediatrics and †Division of Rheumatology (Department of Medicine), NYU Medical Center, New York, \\ NY 10016, U.S.A.
}

\begin{abstract}
Leukotriene $\mathrm{B}_{4}\left[\mathrm{LTB}_{4},(5 S, 12 R)\right.$-hydroxyeicosa-6,14-cis-8,10-trans-tetraenoic acid], a potent mediator of inflammation, is released from neutrophils by agonists that provoke degranulation of the cell. To examine whether degranulation is a necessary requirement for synthesis and metabolism of $\mathbf{L T B}_{4}$ (or of other arachidonate metabolites), we prepared neutrophil-derived cytoplasts (neutroplasts), organelle-depleted vesicles of cytoplasm surrounded by the plasma membrane. In the presence of extracellular $\mathrm{Ca}^{2+}$ with or without exogenous arachidonic acid $(150 \mu \mathrm{M})$, neutroplasts were exposed to the $\mathrm{Ca}^{2+}$ ionophore A23187 $(10 \mu \mathrm{M})$ and the resultant lipoxygenation products of arachidonate were determined. Neutrophils metabolize arachidonic acid to 5-HETE $>15-\mathrm{HETE}>\mathrm{LTB}_{4}>$ all-trans-LTB $\mathrm{LT}_{4}$ isomers. Neutroplast products of

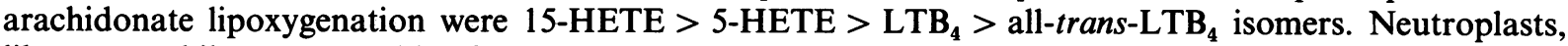
like neutrophils, were capable of converting $\mathrm{LTB}_{4}$ into its 20 -hydroxy and 20-carboxy metabolites. Finally, neutroplasts could utilize intrinsic arachidonate, since the neutroplasts synthesized $\mathrm{LTB}_{4}(30 \mathrm{pmol} / \mathrm{mg}$ of protein) in the absence of added arachidonic acid. The data demonstrate that neutrophil degranulation is not required for synthesis or metabolism of $\mathrm{LTB}_{4}$ by neutrophils.
\end{abstract}

\section{INTRODUCTION}

In response to soluble or particulate stimuli, neutrophils aggregate, move toward a chemoattractant, release toxic oxygen species and produce inflammatory mediators from arachidonate (i.e. LTB $_{4}$ ) (Weissman et al., 1981). It is unclear, however, whether any or all of these processes is linked to degranulation (which is provoked by the same set of stimuli) either as a necessary prerequisite or as a parallel event (Ward \& Becker, 1970; Mehta et al., 1981; Boxer et al., 1982; Fletcher et al., 1982). By using neutrophil-derived cytoplasts or neutroplasts, Roos et al. (1983) and Korchak et al. (1983) have shown that these organelle-depleted cell fragments are capable of aggregating, generating $\mathrm{O}_{2}^{-}$and ingesting particles, despite their lack of granules.

$\mathrm{LTB}_{4}$ is one of the most potent endogenous mediators of inflammation that have been described (Weissmann et al., 1981; Samuelsson, 1983; Lewis \& Austen, 1984). In neutrophils it serves both as a potent chemotactic agent and a complete secretagogue. LTB $_{4}$ is synthesized by neutrophils, as well as by other phagocytic cells, after their stimulation with $\mathrm{Ca}^{2+}$ ionophores or after uptake of particles such as opsonized zymosan (Borgeat \& Samuelsson, 1979a; Rouzer et al., 1980; Claesson et al., 1981). Whether the synthesis and metabolism of $\mathrm{LTB}_{4}$ is linked to the degranulation that accompanies exposure of cells to ionophores or particles has not been examined. To determine whether a stimulus provoking degranulation is required for the generation of $\mathrm{LTB}_{4}$, we have compared neutroplasts with intact neutrophils and found that, when neutroplasts were exposed to the $\mathrm{Ca}^{2+}$ ionophore $\mathrm{A} 23187$ in the presence of external $\mathrm{Ca}^{2+}$, they are as capable as intact cells of synthesizing and catabolizing $\mathrm{LTB}_{4}$; stimulus-induced degranulation is therefore unnecessary.

\section{MATERIALS AND METHODS}

\section{Buffers and reagents}

Hepes buffer comprised $150 \mathrm{~mm}-\mathrm{Na}^{+}, 5 \mathrm{~mm}-\mathrm{K}^{+}, 1.2$

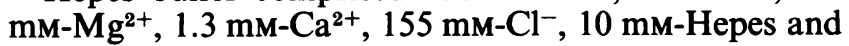
5 mm-glucose, $\mathrm{pH}$ 7.45. Phosphate-buffered saline con-

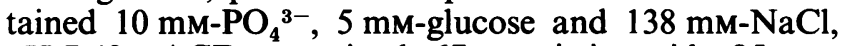
pH 7.42; ACD contained $67 \mathrm{~mm}$-citric acid, $85 \mathrm{~mm}-$ sodium citrate and $110 \mathrm{~mm}$-dextrose. Cytochalasin B was from Aldrich, Ficoll 70 was from Sigma, arachidonic acid was from $\mathrm{Nu}$ Chek and ionophore A23187 was from Calbiochem. Methanol, hexane and propan-2-ol were h.p.l.c. grade from Burdick and Jackson, and anhydrous diethyl ether (h.p.l.c. grade) was from J. T. Baker. Standard $\mathrm{LTB}_{4}$, all-trans-LTB $\mathrm{L}_{4}$ isomers and monoHETEs were kindly given by Dr. P. Borgeat, University of Laval, Quebec, Canada, Dr. J. Rokach, Merk Frosst, Canada, and Dr. C. N. Serhan, Karolinska Institute, Stockholm, Sweden.

\section{Cell separation}

Pools of human polymorphonuclear leucocytes from normal adult volunteers were isolated by centrifugation over a Ficoll/Hypaque cushion and subsequent dextran sedimentation by the method of Boyum (1968). The remaining erythrocytes were removed by hypo-osmotic lysis. Neutrophils were kept in Hepes buffer at room temperature during the period of neutroplast preparation. Platelets were prepared from blood taken from normal

\footnotetext{
Abbreviations used: $\mathrm{LTB}_{4}$, leukotriene $\mathrm{B}_{4}[(5 S, 12 R)$-hydroxyeicosa-6,14-cis-8,10-trans-tetraenoic acid]; (5S,12S)-di-HETE, (5S,12S)-dihydroxyeicosa-6-trans, 14-cis-8-cis, 10-trans-tetraenoic acid; HETE, hydroxyeicosatetraenoic acid; all-trans-LTB ${ }_{4},(5 S, 12 R)$ - and $(5 S, 12 S)$-hydroxyeicosa6,8,10-trans-14-cis-tetraenoic acids; ACD, acid/citrate/dextrose; s.p.- or r.p.-h.p.l.c., straight- or reverse-phase h.p.l.c.; PGB $_{2}$, prostaglandin $\mathbf{B}_{2}$.

$\ddagger$ To whom correspondence and reprint requests should be addressed.
} 
volunteers; aliquots $(6 \mathrm{ml})$ were collected in ACD $(1 \mathrm{ml})$ and were spun at $200 \mathrm{~g}$ in a table-top centrifuge and the platelet-rich plasma was removed. The platelets were washed three times with Hepes buffer/ACD (99:1, v/v, pH 6.5) warmed to $37^{\circ} \mathrm{C}$. They were resuspended in Hepes buffer immediately before use. Platelet activity was verified by aggregation and release of 12-HETE when stimulated with $10 \mu \mathrm{M}-\mathrm{A} 23187$.

\section{Neutroplast preparation}

Neutroplasts were prepared by the method of Roos et al. (1983). Briefly, $1 \times 10^{8}$ neutrophils were mixed with $12.5 \%(\mathrm{w} / \mathrm{v})$ Ficoll 70 containing $5 \mu \mathrm{g}$ of cytochalasin $\mathrm{B} / \mathrm{ml}$ and layered over a discontinuous gradient of $16 \%$ and $25 \%$ Ficoll 70 containing $5 \mu \mathrm{g}$ of cytochalasin $\mathrm{B} / \mathrm{ml}$ that had been prewarmed to $37^{\circ} \mathrm{C}$. A portion of intact neutrophils was removed beforehand to serve as a positive control. The cells were spun at $82000 \mathrm{~g}$ in a Beckman L-2 ultracentrifuge (SW27 rotor; $35^{\circ} \mathrm{C}$; $30 \mathrm{~min}$ ). The layer that formed at the $12.5 \% / 16 \%$-Ficoll interface was removed, washed three times in Hepes buffer and resuspended to a concentration of $9 \times 10^{7}$ neutroplasts $/ \mathrm{ml}$, assuming one neutroplast is formed per neutrophil, as had previously been shown (Korchak et al., 1983). A portion was removed for determination of protein concentration, which was done by the method of Lowry et al. (1951), with lysozyme as the standard.

Neutroplasts and neutrophils were incubated for $15 \mathrm{~min}$ at $37^{\circ} \mathrm{C}$ with or without $150 \mu \mathrm{M}$-arachidonic acid in $0.1 \%$ ethanol and then stimulated with $10 \mu \mathrm{M}-\mathrm{A} 23187$ for $5 \mathrm{~min}$. The reaction was stopped by the addition of 2 vol. of methanol and kept at $-20^{\circ} \mathrm{C}$ overnight.

\section{Extraction and separation procedures}

Lipoxygenase products were isolated by diethyl ether extraction by the method of Borgeat \& Samuelsson $(1979 a, b)$. Briefly, the cell mixture was spun at $1600 \mathrm{~g}$ at $4{ }^{\circ} \mathrm{C}$ in a Sorvall RC3 centrifuge, the supernatant was decanted, and the $\mathrm{pH}$ adjusted to 3.0. The supernatant was then extracted with diethyl ether by using diethyl ether, water and supernatant in the proportions $2: 1: 1$ (by vol.). The resulting water phase was discarded, and the diethyl ether phase was washed twice more with water. The ether phase was evaporated to dryness under a stream of $\mathrm{N}_{2}$ and the products were separated on an Altex Ultrasphere ODS ( $5 \mu \mathrm{m}$ particle size; $4.6 \mathrm{~mm} \times 25 \mathrm{~cm}$ ) r.p.-h.p.l.c. column (Beckman Instruments), a methanol/water/acetic acid $(7500: 2500: 1$, by vol.) solvent system being used. The eluate was monitored at $270 \mathrm{~nm}$ for di-HETEs and $235 \mathrm{~nm}$ for mono-HETEs. Fractions were collected, dried under a stream of $\mathrm{N}_{2}$ and resuspended in methanol until further use. Concentrations of products were determined by measuring u.v. absorbance at $270 \mathrm{~nm}$ for di-HETEs (absorption coefficient 45000 litre $\cdot \mathrm{mol}^{-1} \cdot \mathrm{cm}^{-1}$ ) and at $235 \mathrm{~nm}$ for mono-HETEs (absorption coefficient 30500 litre $\cdot \mathrm{mol}^{-1} \cdot \mathrm{cm}^{-1}$ ). The average recovery of arachidonic acid metabolites as determined by comparing the area under the peak of the r.p.-h.p.l.c. elution profile of $100 \mathrm{ng}$ of $\mathrm{PGB}_{2}$ with that of the same quantity of $\mathrm{PGB}_{2}$ that had been added in six experiments, was $105 \pm 30 \%$. Samples for s.p.-h.p.l.c. were resuspended in $100 \mu \mathrm{l}$ of acid methanol and $800 \mu \mathrm{l}$ of ethereal diazomethane was added. Samples were vortex-mixed and incubated for $15 \mathrm{~min}$ at room temperature. They were evaporated to dryness under $\mathbf{N}_{2}$ and the esterification procedure was repeated. Samples were resuspended in the appropriate h.p.l.c. buffer and run on an Altex Si column $(4.6 \mathrm{~mm} \times 25 \mathrm{~cm})$. Di-HETEs were separated by using a solvent system comprising hexane/propan-2-ol/acetic acid (9500:500:1, by vol.) and monitored at $270 \mathrm{~nm}$. $\omega$-Oxidized compounds were separated by using a hexane/propan-2-ol/acetic acid (9000:1000:1, by vol.) solvent system and monitored at $270 \mathrm{~nm}$. These compounds possessed the triplet absorption maxima of a conjugated triene and were identified by comparison of elution times with published standards. The ratios of the compounds were determined and were used to calculate the molar quantities obtained by the r.p. procedure.

\section{Neutrophil aggregation}

Aggregation was measured as previously described (Craddock et al., 1977). Briefly, $1.25 \times 10^{6}$ cells were stirred in a $100 \mu \mathrm{l}$ silicone-treated cuvette in Hepes buffer containing $5 \mu \mathrm{g}$ of cytochalasin $\mathrm{B} / \mathrm{ml}$. They were stimulated with various concentrations of $\mathrm{LTB}_{4}$ derived from either neutrophils or neutroplasts. Aggregation was measured as an increase in light transmission with respect to time.

\section{RESULTS}

\section{Synthesis of $\mathrm{LTB}_{\mathbf{4}}$ by neutrophils and neutroplasts}

In order to test the hypothesis that intact neutrophils containing granules are required for $\mathrm{LTB}_{4}$ generation, we prepared neutrophil-derived cytoplasts or neutroplasts by the method of Roos et al. (1983). Neutrophils and neutroplasts were incubated with or without A23187 $(10 \mu \mathrm{M})$ for $5 \mathrm{~min}$ after preincubation with arachidonic acid $(150 \mu \mathrm{M})$ in $0.1 \%$ ethanol. Neither unstimulated neutrophils nor neutroplasts made di-HETE products, but both generated mono-HETEs in the presence of added arachidonate (see Table 1). Neutrophils and neutroplasts pretreated with arachidonate and stimulated with A23187 generated both mono- and di-HETES (Table 1; Fig. 1). Fig. 1(a) shows the r.p.-h.p.l.c. chromatogram of a diethyl ether extract of stimulated neutrophils with the mono- and di-HETE fractions identified. Fig. 1(b) shows a representative chromatogram from the paired sample of stimulated neutroplasts. A comparison of Figs. $1(a)$ and $1(b)$ reveals no qualitative difference between the two curves. All peaks generated by neutrophils were also found in the neutroplast preparation. However, the proportions of the various compounds generated by neutrophils and neutroplasts were not identical. Peak d, which was co-eluted with reference $\mathrm{LTB}_{4}$ in both the neutrophil and neutroplast preparations, displayed the characteristic u.v. spectrum of a conjugated triene: triple absorbance maxima at 279, 269 and $259 \mathrm{~nm}$. This peak also contains the compound $(5 S, 12 S)$ di-HETE as reported by Borgeat et al. (1982) and Marcus et al. (1982), which is formed in neutrophil suspensions by a double lipoxygenation reaction. The 5-HETE derived from neutrophils can be acted upon by the 12-lipoxygenase enzyme contributed by any contaminating platelets remaining in the preparation. $\mathrm{LTB}_{4}$ and $(5 S, 12 S)$-di-HETE can, however, be resolved by methyl esterification of the mixture and subsequent chromatography on s.p.-h.p.l.c. We found that the ' $\mathrm{LTB}_{4}$ peak' from neutroplast preparations contained an average of $14 \%(5 S, 12 S)$-di-HETE, as measured by s.p.-h.p.l.c. 
Table 1. Lipoxygenase products generated by neutrophils and neutroplasts with exogenous arachidonic acid

Neutrophils and neutroplasts were incubated for $15 \mathrm{~min}$ at $37^{\circ} \mathrm{C}$ in the presence of $150 \mu \mathrm{M}$-arachidonic acid. They were stimulated for $5 \mathrm{~min}$ with or without $10 \mu \mathrm{M}-\mathrm{A} 23187$ and reaction products were isolated as described in the Materials and methods section. Values are means \pm S.E.M.

\begin{tabular}{|c|c|c|c|c|c|c|c|c|}
\hline & \multicolumn{8}{|c|}{ Content (pmol/mg of protein) } \\
\hline & $\begin{array}{l}\text { 20-Hydroxy- } \\
\text { LTB }_{4}\end{array}$ & $\begin{array}{l}\text { 20-Carboxy- } \\
\text { LTB }_{4}\end{array}$ & $\begin{array}{l}\text { All-trans- } \\
\text { LTB }_{4}\end{array}$ & $\mathrm{LTB}_{4}$ & $\begin{array}{l}(5 S, 12 S)- \\
\text { Di-HETE }\end{array}$ & 15-HETE & 12-HETE & 5-HETE \\
\hline \multicolumn{9}{|l|}{ Neutrophils } \\
\hline $\begin{array}{l}\text { Unstimulated } \\
(n=3)\end{array}$ & 0 & 0 & 0 & 0 & 0 & $160 \pm 100$ & $65 \pm 25$ & $58 \pm 12$ \\
\hline $\begin{array}{l}+10 \mu \mathrm{M}- \\
\text { A23187 }(n=3) \\
\text { Neutroplasts }\end{array}$ & $70 \pm 20$ & $12 \pm 7$ & $180 \pm 20$ & $300 \pm 20$ & $20 \pm 16$ & $490 \pm 270$ & $230 \pm 70$ & $890 \pm 80$ \\
\hline $\begin{array}{l}\text { Unstimulated } \\
(n=4)\end{array}$ & 0 & 0 & 0 & 0 & 0 & $1020 \pm 660$ & $271 \pm 660$ & $130 \pm 70$ \\
\hline $\begin{array}{l}+10 \mu \mathrm{M}- \\
\mathrm{A} 23187(n=4)\end{array}$ & $67 \pm 41$ & $22 \pm 19$ & $135 \pm 50$ & $370 \pm 190$ & $51 \pm 26$ & $410 \pm 2370$ & $716 \pm 370$ & $810 \pm 420$ \\
\hline
\end{tabular}

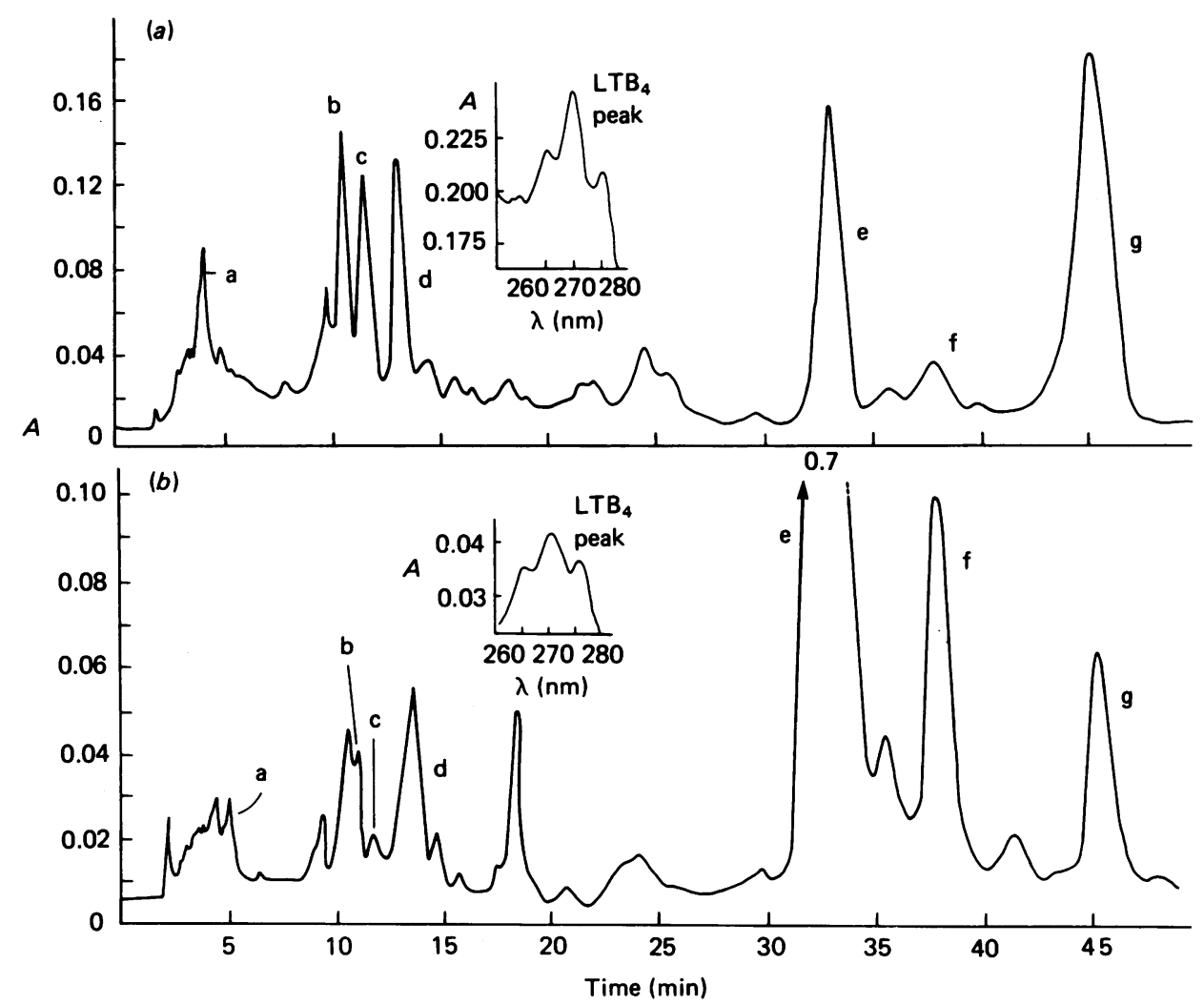

Fig. 1. R.p.-h.p.l.c. of a diethyl ether extract of neutrophils and neutroplasts

Neutrophils or neutroplasts were stimulated with A23187 (10 $\mu \mathrm{M})$ in the presence of arachidonic acid $(150 \mu \mathrm{M})$. The reaction was stopped by the addition of $2 \mathrm{vol}$. of methanol and the supernatant was extracted with diethyl ether (see the Materials and methods section). (a) R.p.-h.p.l.c. of diethyl ether extract of neutrophil preparation. Peaks are as follows: a, void volume containing $\omega$-oxidation products; $\mathrm{b},(5 S, 12 R)$-all-trans-LTB - $_{4}$, $(5 S, 12 S)$-all-trans-LTB ${ }_{4}$; d, LTB LT $_{4}$ e, 15-HETE; f, 12-HETE; g, 5-HETE. The inset is the u.v.-absorption scan of the $\mathrm{LTB}_{4}$ peak. Elution was monitored at $270 \mathrm{~nm}$ for $25 \mathrm{~min}$ and then changed to $235 \mathrm{~nm}$. (b) R.p.-h.p.l.c. of diethyl ether extract of neutroplast preparation. Peaks are labelled as in $(a)$. The inset shows the u.v.-absorption scan of the LTB peak. Elution was monitored at $279 \mathrm{~nm}$ for $25 \mathrm{~min}$ and then changed to $235 \mathrm{~nm}$.

separation. Neutrophil preparations contained $7 \%$ of this product (Table 1).

To confirm that neutroplast-generated $\mathrm{LTB}_{4}$ possessed biological activity, we tested it for its ability to elicit neutrophil aggregation. Although it was not possible to perform a complete dose-response analysis, owing to the small quantities of $\mathrm{LTB}_{4}$ produced by each preparation of neutroplasts, equal concentrations of neutrophil and 


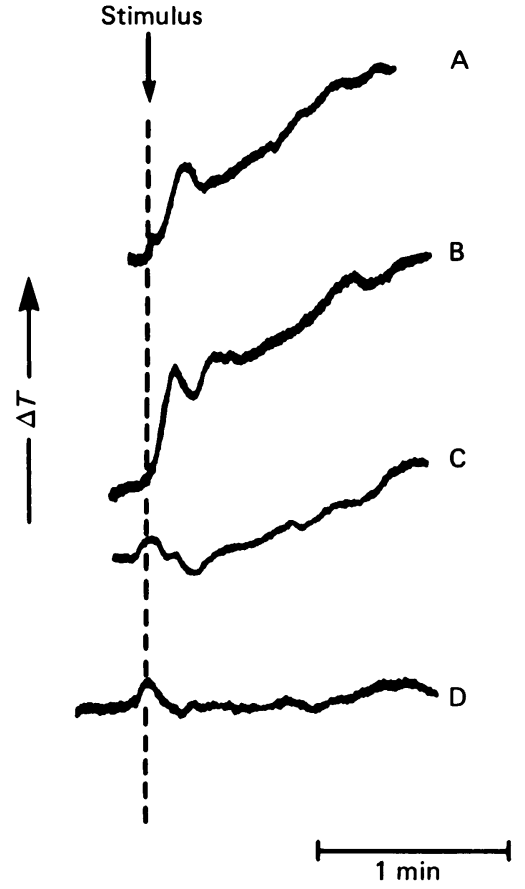

Fig. 2. Aggregation of neutrophils by $\mathrm{LTB}_{4}$

Aggregation was monitored continuously as changes in light transmission $(\Delta T)$ of a stirred suspension of neutrophils that had been incubated for $5 \mathrm{~min}$ at $37^{\circ} \mathrm{C}$ with cytochalasin B at $5 \mu \mathrm{g} / \mathrm{ml}$ before addition of stimulus. Curves are 'stacked' for comparison. A, neutrophil-derived $\mathrm{LTB}_{4}(0.1 \mu \mathrm{M}) ; \mathrm{B}$, neutroplast-derived $\mathrm{LTB}_{4}(0.1 \mu \mathrm{M}) ; \mathrm{C}$, neutroplast-derived $\mathrm{LTB}_{4}(50 \mathrm{nM}) ; \mathrm{D}$, all-trans-LTB $\mathrm{LT}_{4}$ $(0.1 \mu \mathrm{M})$.

neutroplast $\mathrm{LTB}_{4}$ consistently produced the same degree of neutrophil aggregation (Fig. 2). All-trans-LTB ${ }_{4}$, here derived from neutroplasts, caused no neutrophil aggregation at the highest concentration used (Fig. 2).

\section{Metabolism of $\mathrm{LTB}_{4}$ by neutrophils and neutroplasts}

During cell activation, $\mathrm{LTB}_{4}$ is converted into its more polar metabolites, the 20-hydroxy and 20-carboxy compounds, which possess less activity with respect to neutrophil activation than LTB $_{4}$ (Hansson et al., 1981; Lindgren et al., 1981, 1982; Serhan et al., 1982; Ford-Hutchinson et al., 1983). To determine whether neutroplasts also retain the ability to convert $\mathrm{LTB}_{4}$ into its terminal oxidation products, the initial fractions from the r.p. separation were pooled, evaporated to dryness, methyl-esterified and separated by s.p.-h.p.l.c. Both 20-hydroxy-and 20-carboxy-LTB $\mathrm{TB}_{4}$ were isolated from the neutroplast preparation in the same proportion as from the neutrophils (Table 1).

\section{Utilization of intrinsic arachidonate stores}

The experiments above were all performed in the presence of added arachidonic acid. Having shown that neutroplasts can utilize free arachidonate to generate $\mathrm{LTB}_{4}$, we next examined whether neutroplasts were able to mobilize intrinsic arachidonic acid and to utilize it in forming lipoxygenase products. Neutroplasts exposed to A23187 $(10 \mu \mathrm{M})$ proved capable of forming $\mathrm{LTB}_{4}$, albeit in much smaller quantities than those generated in the presence of exogenously added arachidonate $(30 \mathrm{pmol} / \mathrm{mg}$ of protein as against $300 \mathrm{pmol} / \mathrm{mg}$ of protein; Tables 1 and 2).

Neutrophil and neutroplast preparations are always contaminated by a small, but detectable, number of platelets, as demonstrated by the constant finding of 12-HETE among the lipoxygenase products. Previous work in this laboratory has shown that, after activation, platelets release free arachidonate, which can be used as a precursor by intact neutrophils for the generation of LTB $_{4}$ (Marcus et al., 1982). In order to determine whether the $\mathrm{LTB}_{4}$ found in the neutroplast preparations was generated from the intrinsic arachidonic acid of the neutroplast or from arachidonate released by the contaminating platelet population, we added large numbers of platelets to a neutroplast preparation, stimulated the mixture with the ionophore A23187, and isolated the lipoxygenase products. Neutroplasts did not utilize platelet arachidonate in significant quantities, as shown in. Table 2. Neutroplasts generated the same amount of $\mathrm{LTB}_{4}$ with and without added platelets. The quantity of 12-HETE produced increased by more than 60-fold, showing that the platelets were active. In addition, the amount of $(5 S, 12 S)$-di-HETE (the double-lipoxygenation product) increased over 10 -fold.

\section{DISCUSSION}

Many neutrophil functions have been linked to degranulation; these include aggregation, $\mathrm{O}_{2}^{-}$generation and the mobilization of receptors for chemotactic factors (Ward \& Becker, 1970; Mehta et al., 1981; Oseas et al., 1981; Fletcher et al., 1982). Alternatively, Roos et al.

Table 2. Lipoxygenase products generated by neutroplasts and platelets (without exogenous arachidonic acid)

Neutroplasts were incubated for $5 \mathrm{~min}$ at $37^{\circ} \mathrm{C}$ with $10 \mu \mathrm{M}-\mathrm{A} 23187$ with or without platelets from $4 \mathrm{ml}$ of platelet-rich plasma. Reaction products were isolated as described in the Materials and methods section. All values are means \pm S.E.M. $(n=3)$.

\begin{tabular}{lcccc}
\hline & \multicolumn{4}{c}{ Content (pmol/mg of protein) } \\
\cline { 2 - 4 } & LTB $_{4}$ & $(5 S, 12 S)$-di-HETE & 12-HETE & 5 -HETE \\
\hline $\begin{array}{c}\text { Neutroplasts + } 10 \mu \mathrm{M}- \\
\text { A23187 }\end{array}$ & $30 \pm 12$ & $0.4 \pm 0.4$ & $5 \pm 2$ & $45.0 \pm 28$ \\
$\begin{array}{c}\text { Neutroplasts + platelets } \\
+10 \mu \mathrm{M}-\mathrm{A2} 23187\end{array}$ & $32 \pm 20$ & $90 \pm 40$ & $587 \pm 330$ & $35.3 \pm 28$ \\
$\begin{array}{c}\text { Platelets+10 } \mu \mathrm{M}- \\
\text { A23187 }\end{array}$ & 0 & 0 & $830 \pm 75$ & 0
\end{tabular}


(1983) and Korchak et al. (1983), by means of neutroplast preparations, have shown that aggregation, release of toxic oxygen products, phagocytosis and changes in membrane potential in the neutrophil can proceed in the absence of degranulation. Preparations of cytosol from various cells and cell lines have been shown to generate various products of the lipoxygenase pathways. Interpretations of these experiments are fraught with difficulty, since different methods of preparing cytosol can lead to opposite conclusions (Shak \& Goldstein, 1985; Soberman et al., 1985), possibly owing to contamination with cell membranes or organelle fragments and contents. To examine whether granules and/or an intact mechanism of degranulation are required for leukotriene synthesis and catabolism, we utilized neutroplasts. We have found that neutroplasts synthesize 5-lipoxygenase products, including $\mathrm{LTB}_{4}$. Neutroplasts also contain the enzymes necessary to metabolize $\mathrm{LTB}_{4}$ to the more-polar, less-active products: 20-hydroxy-and 20-carboxy-LTB T $_{4}$. We do not consider it appropriate to quantitatively compare neutroplast and neutrophil synthesis of these compounds. In addition to the donor-to-donor variation in the quantity of lipoxygenase products produced by neutrophils, there is also significant donor-related variation in the size and protein content of their neutroplasts; hence the variability of lipoxygenase products produced by neutroplasts is large. However, it is important to note that neutroplasts produce a significant amount of 5-lipoxygenase products in ratios similar to those generated by neutrophils.

Finally we havedemonstrated not only that neutroplasts retain the ability to synthesize lipoxygenase products after the initial step of arachidonic acid liberation, but that these cell fragments can form the same products in the absence of added arachidonate. Previous work has demonstrated that neutrophils can utilize arachidonic acid released from stimulated platelets to synthesize LTB $_{4}$ (Marcus et al., 1982). When suspensions were enriched in platelets (over 60 -fold as measured by the increment in 12-HETE synthesis), no increase in the synthesis of $\mathrm{LTB}_{4}$ was found. Failure of neutroplasts to form $\mathrm{LTB}_{4}$ was not simply due to saturation of the lipoxygenase enzymes, since ionophore provoked a concomitant increase in the double-lipoxygenase product, $(5 S, 12 S)$-di-HETE. Moreover, adding free arachidonic acid (cf. Tables 1 and 2) resulted in enhanced synthesis of both $\mathrm{LTB}_{4}$ and $(5 S, 12 S)$-di-HETE.

Stimulated neutroplasts, in the presence of added arachidonate, generate larger quantities of 15-HETE than do neutrophils. In the absence of added arachidonate, the quantity of 15-HETE is almost undetectable. It is possible that, in contrast with added arachidonate, intrinsic arachidonic acid metabolized during stimulation may not be available to the 15-lipoxygenase enzyme. We have not, however, determined whether neutroplast 15-HETE is enzymically produced by examining the chirality of the - $\mathrm{OH}$ grouping either by oxidative ozonolysis or application to a chiral column. An alternative explanation is that the free arachidonate spontaneously reacts with active oxygen products produced by neutroplasts to form 15-HETE. Borgeat \& Samuelsson $(1979 a)$, in their initial observations on neutrophil-derived 15-HETE, noted that the stereospecificity of this compound was less than would be expected if the 15-HETE was synthesized solely by means of an enzymic reaction and suggested that some 15-HETE may have been generated by non-specific oxidation. At present we cannot rule out either of these two possibilities.

We have demonstrated that neutroplasts can generate the more polar metabolites of $\mathrm{LTB}_{4}$, the 20-hydroxy-and 20-carboxy-leukotrienes. These products are less active than $\mathrm{LTB}_{4}$ in neutrophil aggregation, $\mathrm{O}_{2}{ }^{-}$and enzymerelease assays, and $\mathrm{LTB}_{4}$ may be inactivated in vivo by $\omega$-oxidation (Hansson et al., 1981; Lindgren et al., 1981, 1982; Serhan et al., 1982; Ford-Hutchinson et al., 1983). Chacos et al. (1982) and Oliw et al. (1982) have shown that liver microsomes can oxidize arachidonate, and it has been suggested by Shak \& Goldstein $(1984,1985)$ that cytochrome $P-450$ is the site of the terminal oxidation of LTB $_{4}$ and $(5 S, 12 S)$-di-HETE. At present, we have no information as to whether neutroplasts contain what would constitute a 'microsomal fraction' isolated from neutrophils. Since neutroplasts do, however, form the $\omega$-oxidation products of leukotrienes, they contain the enzymes required for further metabolism of di-HETEs.

In summary, neutroplasts respond to the $\mathrm{Ca}^{2+}$ ionophore by mobilizing intrinsic arachidonate, activating the lipoxygenase pathway of arachidonate metabolism to synthesize mono- and di-HETE products, and metabolizing di-HETEs to their $\omega$-oxidation products. LTB $_{4}$ synthesis and metabolism, therefore, proceeds unimpaired in the absence of organized intracellular structures.

This study was supported by grants from the National Institutes of Health (AM 11949, AM 01431, and HL 19721 to G.W.) and from Upjohn Pharmaceuticals, Medical Sciences Division, Kalamazoo, MI, U.S.A.

\section{REFERENCES}

Borgeat, P. \& Samuelsson, B. (1979a) Proc. Natl. Acad. Sci. U.S.A. 76, 2148-2152

Borgeat, P. \& Samuelsson, B. (1979b) J. Biol. Chem. 254, 2643-2646

Borgeat, P., Fruteau de Laclos, B., Picard, S., Vallerand, P. \& Sirois, P. (1982) in Leukotrienes and other Lipoxygenase Products (Samuelsson, B. \& Paoletti, R. eds.), pp. 45-51, Raven Press, New York

Boxer, L. A., Coates, T. D., Haak, R. A., Wolach, J. B., Hoffstein, S. \& Baihner, R. L. (1982) N. Engl. J. Med. 307, 404-410

Boyum, A. (1968) Scand. J. Clin Lab. Invest. Suppl. 97, 21, 77-89

Chacos, N., Falck, J. R., Wixtrom, C. \& Capdevila, J. (1982) Biochem. Biophys. Res. Commun. 104, 916-922

Claesson, H.-E., Lundberg, U. \& Malmsten, C. (1981) Biochem. Biophys. Res. Commun. 99, 1230-1237

Craddock, P. R., Hammerschmidt, D. E., Dalmasso, A. P., White, J. G. \& Jacob, H. S. (1977) J. Clin. Invest. 60, 260-264

Fletcher, M. P., Seligmann, B. E. \& Gallin, J. I. (1982) J. Immunol. 105, 1057-1067

Ford-Hutchinson, A. W., Rackham, A., Zamboni, R., Rokach, J. \& Roy, S. (1983) Prostaglandins 25, 29-37

Hansson, G., Lindgren, J. A., Dahlen, S.-E., Hedqvist, P. \& Samuelsson, B. (1981) FEBS Lett. 130, 107-112

Korchak, H. M., Roos, D., Giedd, K. N., Wynkoop, E. M., Vienne, K., Rutherford, L. E., Buyon, J. P., Rich, A. M. \& Weissmann, G. (1983) Proc. Natl. Acad. Sci. U.S.A. 80, 4968-4972

Lewis, R. A. \& Austen, K. F. (1984) J. Clin. Invest. 73, 889-897

Lindgren, J. A., Hansson, G. \& Samuelsson, B. (1981) FEBS Lett. 128, 329-335

Lindgren, J. A., Hansson, G., Claesson, H.-E. \& Samuelsson, B. (1982) in Leukrotrienes and other Lipoxygenase Produces (Samuelsson, B. \& Paoletti, R., eds), pp. 53-60, Raven Press, New York 
Lowry, O. H., Rosebrough, N. J., Farr, A. L. \& Randall, R. J. (1951) J. Biol. Chem. 193, 265-275

Marcus, A. J., Broekman, M. J., Safier, L. B., Ullman, H. L., Islam, N., Serhan, C. N., Rutherford, L. E., Korchak, H. M. \& Weissman, G. (1982) Biochem. Biophys. Res. Commun. 109, 130-137

Mehta, J., Mandell, B., Kleyman, T. \& Spilberg, I. (1981) Inflammation (N.Y.) 5, 89-101

Oliw, E. H., Guengerich, F. P. \& Oates, J. A. (1982) J. Biol. Chem. 257, 3771-3781

Oseas, R. S., Allen, J., Yang, H.-H., Baehner, R. L. \& Boxer, L. A. (1981) Infect. Immun. 33, 523-526

Rouzer, C. A., Scott, W. A., Cohn, Z. A., Blackbarn, R. \& Manning, J. M. (1980) Proc. Natl. Acad. Sci. U.S.A. 77, 4928-4932

Roos, D., Voetman, A. A. \& Meerhof, L. J. (1983) J. Cell Biol. 97, 368-377

Received 11 July 1985/6 September 1985; accepted 26 September 1985
Samuelsson, B. (1983) Science 220, 568-575

Serhan, C. N., Radin, A., Smolen, J. E., Korchak, H. M., Samuelsson, B. \& Weissman, G. (1982) Biochem. Biophys. Res. Commun. 107, 1006-1012

Shak, S. \& Goldstein, I. M. (1984) J. Biol. Chem. 259, 10181-10187

Shak, S. \& Goldstein, I. M., (1985) J. Clin. Invest. 76,12181228

Soberman, R. J., Harper, T. W., Murphy, R. C. \& Austen, K. F. (1985) Proc. Natl. Acad. Sci. U.S.A. 82, 2292-2295

Ward, P. A. \& Becker, E. L. (1970) J. Immunol. 105, 10571067

Weissmann, G., Korchak, H. M., Perez, H. D., Smolen, J. E., Goldstein, I. M. \& Hoffstein, S. T. (1981) in Membranes, Molecules, Toxins and Cells (Bloch, K., Bolis, L. \& Tosteson, D. C., eds.), pp. 175-191, PSG Publishing Co., Boston, Bristol and London 